\title{
Post-Tenure Reflections on Community-Engaged Scholarship in a Psychology Research Setting
}

Farrah M. Jacquez

\begin{abstract}
Community-engaged scholarship emphasizes community partnership in the teaching, research, and service roles faculty pursue. Traditionally, psychological research places the highest value on tightly controlled, laboratory-based research led by faculty as "expert" and community as "subjects." The difference in values between traditional research and community-engaged research can serve as a paradigm-level barrier to community-engaged scholarship for psychologists working in research settings. I discuss my personal experience as a faculty member with a community-based participatory research (CBPR) orientation and describe four suggestions to increase community-engaged scholarship among psychology researchers in similar highresearch institutions: (a) revise promotion and tenure documents to recognize it; (b) update IRB reviews to support it; (c) earmark internal funding specifically for it; and (d) create networks to spread it.
\end{abstract}

Keywords: community-engaged participatory research; community-engaged scholarship; psychology; health disparities

\section{Introduction}

Like most students in the last fifty years who pursued a Doctor of Philosophy degree in clinical psychology, I was trained in a scientist-practitioner model that emphasized the integration of research and clinical practice (Beck et al., 2014). The foundation of the scientist-practitioner model is the idea that training in both research and clinical skills will be the best professional preparation for a psychologist, no matter what type of career they go on to pursue. Clinicians can provide higher quality care if they are active, knowledgeable consumers of scientific information and academic psychologists will generate more relevant, applicable scientific evidence if their research is informed by real clients.

Community-engaged research is a collaboration between academic and community partners to create and disseminate knowledge for both academic and community benefit (Carnegie Foundation, 2018). One might imagine that psychology's scientist-practitioner model could serve as a helpful framework for community-engaged research by simply replacing "clients" with "communities" in the conceptualization of ideals. Researchers who choose to work with community organizations and resident stakeholders will conduct research that directly speaks to community problems. Psychologists working in communities using evidence-based practices will have more power to change the structures and systems necessary to promote positive community change. 
Despite the seemingly easy transition from the scientist-practitioner model to communityengaged research, clinical psychology as an academic discipline has been slow to accept community-engaged research as valid science. The distrust stems primarily from a difference in values that can be framed in terms of the trade-off between internal and external validity. In every scientific inquiry, the researcher must balance the need to tightly control all aspects of the study to reduce confounding variables that muddy results (internal validity) with the desire to have the results apply to the real world (external validity). In psychology, the balance between internal and external validity when designing research studies is often referred to as "the experimenter's dilemma."

Traditionally, psychology research has placed a very high value on internal validity. For example, in intervention research, lab-based randomized controlled trials are considered the gold standard because they maximize confidence that significant findings are a result of the treatment and not because of spurious factors. Internal validity is critical to consider because we need to be sure that the treatments we are delivering actually do help people. However, the pervasive wicked problems that persist despite considerable funding and effort to combat them (e.g., obesity, drug abuse, health disparities) suggest that the interventions developed through traditional research methods are simply not working outside the laboratory setting.

Community-engaged researchers tend to place more weight on external validity in the interest of tangible benefits in the community. Although a community-engaged scientist will try to control as many factors as possible when conducting research to maximize internal validity, ultimately if the treatment doesn't work in the real world, it is not worth developing.

The difference in values between traditional research and community-engaged research can serve as a paradigm-level barrier to community-engaged scholarship for psychologists working in research settings. Partnering with community members in research differs from traditional research at almost every point in the process, including deciding which research questions to ask, who gets funding, how to collect data, and where to disseminate results. At each point, the researcher necessarily compromises control so that the research is more relevant and has greater reach in the community (Balazs \& Morello-Frosch, 2013). In comparison with the disciplines of public health and education, psychology has been slower to accept a balance shift toward less control (Bogart \& Uyeda, 2009). However, the tides appear to be turning.

A recent article in American Psychologist, the official journal of the American Psychological Association, made the case for equitable involvement of community members in psychological research (Collins et al., 2018). Surprisingly few psychologists within academia are working from a community-based participatory research (CBPR) lens, so the introduction to this research orientation in the most widely distributed journal in psychology marks a major milestone. The authors (which include both researchers and community partners) describe several distinct advantages of community-engaged research that respond directly to the internal-external validity trade-off. In particular, they highlight the potential for community-engaged research to close the research-practice gap, to improve validity of research methods, and to increase effectiveness of interventions. I have found these same benefits in my own work. In the remainder of this paper, I will discuss my personal experience as a faculty member with a CBPR research orientation and 
make suggestions to increase community-engaged scholarship among psychology researchers in similar high-research institutions.

\section{Personal Experience of a Community-Engaged Research Psychologist}

For the past ten years, I have worked as a professor in the Psychology Department at the University of Cincinnati, a Research 1 institution with a total student enrollment of about 45,000. I have been doing community-engaged scholarship to fulfill UC's research, teaching, and service expectations for my faculty role (Jacquez, 2014). In my research, I have worked with Latino immigrants, community organizers, neighborhood leaders, and youth to develop interventions for health equity. In my teaching, I partner for each class with a community organization to allow students to use research skills to help agencies reach their goals. My service activities focus on serving on community boards and leading activities to help recruit and retain underrepresented minority students and faculty. I was fortunate to receive the Lynton Award for Community Engagement for Early Career Faculty in 2013, an honor that was extremely helpful in my bid for tenure. I do not have colleagues reviewing my materials who engage in community-based participatory research, so the external validation of the Lynton Award helped to explain my impact at both the departmental and college levels of tenure review. The Lynton Award helped to legitimize my research and convince promotion and tenure reviewers, even those unfamiliar with the field of community-engaged scholarship, of the value of my approach.

In the time I have spent as a faculty member, the enthusiasm with which my work and community-engaged research in general is received has increased rather dramatically. I believe there are two primary drivers in this shift. Firstly, the funding landscape has changed. Funders like the Robert Wood Johnson Foundation, the Patient-Centered Outcomes Research Institute (PCORI), and even some requests for proposals from the National Institutes of Health are including community engagement as a required element in grant proposals. These requirements have placed a higher value on faculty who have demonstrated expertise in community-engaged work. Secondly, I and other community-engaged faculty have identified strategies to disseminate our work in ways that satisfy traditional research expectations, thereby making communityengaged research more mainstream.

For example, in our five-year partnership with Latino immigrants, we have published seven articles, including results of the work (Jacquez et al., 2016; Jacquez, Vaughn \& Suarez-Cano, 2018; Topmiller et al., 2016; Zhen-Duan, Jacquez \& Vaughn, 2017), participatory methodologies we've used with Latino immigrants to collaborate (Vaughn et al., 2016) and descriptions of the process of working together over time (Vaughn et al., 2016; Vaughn et al., 2017; Vaughn, Jacquez \& Zhen-Duan, 2018). By publishing community-engaged work in traditional research journals, I am part of a movement of community-engaged researchers who are demonstrating that partnering with community members is "real" scientific research that can and should be valued in academia. At the same time, grant funders are requiring that researchers include community members to increase translation and potential for real world change. Together, researchers and grant funders are helping to not only make community engagement more acceptable, but to make it an expectation for research that can lead to action. 


\section{Promoting Community-Engaged Research within Research 1 Institutions}

Funding mechanisms and researcher savvy ${ }^{i}$ have changed in ways that encourage communityengaged research. Nevertheless, research 1 institutions have been slower to institute policies that promote this work. The Carnegie Foundation currently classifies 115 doctoral-granting universities throughout the United States as Research 1 institutions, or those with the highest research activity. The Carnegie Elective Classification for Community Engagement assesses institutional commitment to community engagement and the process of self-study involved in the application process allows institutions to revitalize their civic and academic missions. There are 316 campuses nationally that have been awarded the classification since 2006 (Carnegie Foundation for the Advancement of Teaching, 2015). Among Research 1 institutions, 53\% $(n=61)$ have received the Carnegie Classification for Community Engagement at one of the two eligible points in the last decade (Carnegie Classification, 2018). Although the community engagement classification is elective, it represents an evidence-based documentation of institutional practice and suggests an institution's interest in self-study and quality improvement in community-engagement (Swearer Center, 2018).

Furthermore, my experience in a STEM discipline at a Research 1 institution is consistent with the observations of fellow community-based participatory researchers in academic medicine. who have posited that policies and procedures will need intentional shifts in order to increase the number of faculty doing community-engaged research (Nyden, 2003; Allen et al., 2010). In reflecting on the primary barriers and facilitators to my community-engaged scholarship as a faculty member over the last decade, I have identified the top four factors that have served as barriers or facilitators to my work: promotion and tenure policies, Institutional Review Boards, professional networks, and internal funding mechanisms. Based on these factors, I outline specific recommendations for research institutions to support faculty in their pursuit of rigorous community-engaged research.

Factor 1: Revise promotion and tenure documents to recognize community-engaged research

One of the often-cited strategies to promote community-engaged research is to revise promotion and tenure strategies to recognize this type of work (Israel, Schulz, Parker \& Becker, 2001). However, the traditional STEM disciplines and academic medicine settings where many health researchers are employed have not changed their policies. Since the days when I went through the tenure process, two institutions with which I am affiliated have made major revisions to their promotion and tenure policies to make room for different kinds of research impact. In my home department of Psychology at the University of Cincinnati, our 40-person faculty took on a laborious collaborative revision of our Reappointment, Promotion, and Tenure criteria in 2014. In faculty meetings over the course of a year, we discussed the specific language in our criteria that could be adjusted to include community-engaged research. When I went up for tenure in 2013, the criteria for research and publishing was:

It is traditional in psychology to focus on refereed journal articles. While these are important, we also look for appropriate presentation of research. Typically, this will mean articles, but it could also include books, chapters, technical reports, or other suitable 
forms of publications. The candidate may offer evidence on the appropriateness of the outlets.

Following lengthy discussions about how we could uphold the standards of our scientific discipline while still having room for community impact, we revised the research and publishing language to:

The Department of Psychology includes a diverse group of scholars representing a variety of disciplines and areas of focus. It is critical that, regardless of a faculty member's area of focus, his or her dossier clearly documents excellence in research. The field of psychology has traditionally focused on refereed journal articles and grants as the primary measures of research productivity. While peer-reviewed journal publications are important, we also look for other appropriate presentations of research, which could also include books, chapters, technical reports, or other suitable research products. We understand that some of our tenure-track faculty are practicing in subfields in which it is not traditional to seek federal research funding as PI or to disseminate their research primarily in peer-reviewed journals. In these situations, the candidate must offer evidence in the dossier of 1) what the standard of research excellence is in the subfield and 2) how this standard has been met.

These changes recognize the diversity of research within psychology as a discipline and providing a specific mechanism for faculty to demonstrate their excellence in nontraditional ways. Where the psychology faculty focused on a general shift in promotion and tenure criteria, another example from Pediatrics at Cincinnati Children's Hospital and Medical Center focused on the inclusion of community-engaged research and community-based participatory research (CBPR) more specifically. In the section of their Reappointment, Promotion, and Tenure criteria focused on participation in research or other scholarly activities, they added several sentences and a phrase to include a broader spectrum of research (relevant added sections are italicized):

Research and scholarly activities are broadly defined, and include basic, clinical, or translational; health disparities; community-engaged; biostatistical or informatics; quality, safety and outcomes; behavioral; and health services research. Participation in clinical trials or other investigations that lead to the translation of intellectual property into potentially commercially viable products are also valued. Given that interdisciplinary team activities are increasingly recognized as important to the future of biomedical science, participation or leadership in collaborative research/team science are valued in the promotion process. In addition, it is well recognized that collaboration between academic and community partners can enhance translation of scientific knowledge for clinical and community programs; therefore, the efforts of faculty working with community organizations to improve public health are also values. Collaborative research is evidenced by participation in local or regional multidisciplinary, interdisciplinary, or multicenter studies; collaboration between academic and community partners; or participation in multi-site research, clinical improvement, learning or safety networks. External support for research or scholarly activities is encouraged but not required. Solely referring patients to clinical trials is not sufficient to achieve this criterion. 
The revisions came about in consultation with the Center for Clinical and Translational Science and Training (CCTST), our Cincinnati-area Clinical and Translational Science Award (CTSA). Like all 57 National Institute of Health-funded CTSAs around the country, the CCTST has a Community Engagement Core that focuses on integrating academic and community resources for community benefit. Faculty in our Community Engagement core advised the department of Pediatrics in the revision of their promotion criteria to explicitly acknowledge the benefit of working with community partners to improve scientific knowledge and better disseminate it so that it can improve health outcomes.

The University of Cincinnati Psychology Department and the Cincinnati Children's Hospital and Medical Center Department of Pediatrics are two examples of departments that have improved their policies to allow faculty to show impact through community-engaged research. However, the road to changing policies even across these two institutions is long and complex. At UC, there are five colleges and more than 50 departments, each with their own promotion and tenure criteria. Although Psychology has changed our criteria to pave the way for community-engaged scholarship, to my knowledge no other department has made similar revisions. To make changes in just one institution is a mammoth undertaking requiring investment from stakeholders across disciplines.

Factor 2: Require community-engaged research expertise on Institutional Review Boards (IRBs)

Bring together any group of community-engaged researchers and you will inevitably hear a conversation about the frustrations working with IRB systems that have rigid rules and procedures to protect human subjects in traditional scientist-subject relationships. Like other researchers, I have been personally challenged in managing the ethics of working in community partnerships with the human subjects protection policies and procedures implemented by the IRB (Wilson, Kenny \& Dickson-Smith, 2018). One review of challenges to community-based participatory research and IRB found consistent barriers across all studies (Tamariz et al., 2015).

The primary issues stem from the difference between traditional research paradigms and the more iterative, shared-decision making that happens in community-engaged research. IRBs overwhelming evaluate research that is designed, implemented, analyzed, and disseminated by an academic "expert." Therefore, their role is to protect the human beings who serve as subjects in the research. In community-engaged research, research "subjects" are instead partners in forming the questions, making decisions about research design, and getting the word out about results. Most IRBs simply do not have a process to evaluate CBPR projects. The IRB at my institution has shown an interest in promoting community-engaged research and has attended meetings across campus to better understand how to support this work, but we still do not have a concrete set of procedures that can be applied specifically to community-engaged research.

As has been recommended by other researchers (Tamariz et al., 2015) and professional organizations like Community-Campus Partnerships for Health (Shore et al., 2014), I believe that having individuals with community-engaged research expertise and non-academic community representatives on IRBs could help with the review process. Ideally, these academic and livedexperience experts could help develop new policies and procedures to delineate the research 
ethics involved in community-based participatory research (Mikesell, Bromley \& Khodyakov, 2013).With community members serving on IRB review panels, community-engaged researchers could be more confident that the IRB was truly evaluating their research for what it is: a collaborative approach that uses research methods to solve real-world problems.

Factor 3: Earmark internal funding mechanisms for community-engaged research

One of the most difficult aspects of starting a tenure-track faculty position as a communityengaged researcher is the ever-looming expectation for grant funding. The first two reappointment reviews happen after 18 months and about four years respectively. Research faculty are expected to have funding to report at these reviews. Community-engaged research can simply take more time to get started. Collaborative relationships between researchers and community members take time to develop and the process of sharing decision-making takes more time than researcher-led projects. Unfortunately, few grant mechanisms fund partnership development to allow community members and academic partners to co-create research projects.

Our Cincinnati-area CTSA organization has developed grant and training mechanisms over the past nine years to support community-academic partnerships and research. As Co-Director of Research for the Community Engagement Core of the Center for Clinical and Translational Science and Training (CCTST), I have overseen the Community Health Grant program for the past eight years, which funds projects up to $\$ 20,000$ that are conceived and conducted by community-academic partnerships. Because we often received applications from teams that had the potential to be great partners, but were not yet ready to do a full research project, two years ago we developed the Partnership Development Grant to fund new partnerships up to $\$ 5000$ as they plan a project or collect pilot data. On the community side, we offer the popular Community Leaders Institute (CLI), a six week training series designed to enhance academic-community research, integrate the interests of community leaders and researchers, and build research capacity and competencies within the community (Crosby, Parr, Smith \& Mitchell, 2013). The CLI has formed a network of research-savvy community leaders ready to partner for change in our community.

Taken together, the CCTST's grant programs provide small but significant internal funding mechanisms to support community-engaged research that can be particularly helpful for junior faculty members still developing their community partnerships. I was fortunate to receive two Community Health Grants early in my career. These awards allowed me to form relationships with community partners with whom I still work today, to add grant funding to my CV for my reappointment reviews, and to collect pilot data that became the basis for national-level funding. Universities and academic medical centers that truly value community-engaged research should create funding that is specifically earmarked for this type of work. Ideally, grant proposals should be reviewed by both academic and community members to evaluate the degree to which research is mutually beneficial to both scientific and community interests.

Factor 4: Create networks of community-engaged scholars across disciplines

Like most disciplines, psychology can be pedigree-driven. Most research psychology training programs work on a mentorship model in which graduate students are recruited into doctoral 
programs to work with a particular mentor. Students often go on to internships and postdoctoral fellowships with other students who have worked with their mentor, or mentors of their mentor. A tight-knit community develops, with everyone going to the same conferences and building on one another's research. I was trained in this model and was extremely fortunate to have an excellent graduate mentor who prepared me well for a path into pediatric psychology. Therefore, I was able to complete an internship at the \#1 ranked children's hospital in the country and an NIH-funded pediatric psychology postdoctoral fellowship. I was well positioned to join the tight-knit group of psychologists I had trained to be a part of.

However, along the way I discovered community-engaged participatory research. None of the students or faculty with whom I had trained had ever conducted CBPR; many were downright skeptical of my "outreach projects", which they considered unscientific. My faculty department was supportive of me taking my own path, but I had lost the network of mentors and students to collaborate with me on the journey.

Because community-engaged research is an emerging field, I have noticed that many departments across my campus have just one or two people interested in this type of work. Because I am part of a large campus with an adjacent academic medical center, there are enough of us interested in community-engaged work that we have found each other. Many of us collaborate and we have started to form mechanisms to network and support one another. For example, in the College of Arts \& Sciences at UC, we have created The Cincinnati Project (http://thecincyproject.org/), a collaborative that harnesses the expertise and resources from the University of Cincinnati faculty and students, and from Cincinnati community members, nonprofits, governments and agencies in order to conduct research that will directly benefit the community.

Through The Cincinnati Project and the CCTST, I have been able to join a network of faculty and community members in Cincinnati doing community-engaged work, which has been immensely helpful in both tangible and abstract ways. I have developed concrete skills in working with the IRB, applying for grants, and meeting new partners to conduct research, but I have also felt supported, understood, and validated by colleagues. On a national level, I have recently joined the Board of Directors for Community-Campus Partnerships for Health (CCPH), a nonprofit membership organization that promotes health equity and social justice through partnerships between communities and academic institutions (https://www.ccphealth.org/). $\mathrm{CCPH}$ provides a professional home to many academic and community partners who, like me, are driven by partnership processes rather than a discipline-specific allegiance.

Institutions who are serious about cultivating community-engaged research should provide funded, structured networks for individuals across disciplines on their campus to do this work. They should also provide funding and support for faculty members to join national collaboratives like $\mathrm{CCPH}$ to allow community-engaged researchers to connect with colleagues across the country who also prioritize participatory, partnered research methods. 


\section{Conclusion}

Since I entered the job market in 2008, I have noticed that universities and academic medical centers across the country are reinvigorating their dedication to community engagement. These changes are often clearly seen in marketing materials expressing a commitment to community partnerships, but are less visible in institutional support for faculty members doing communityengaged research.

In order for community-engaged scholarship to move from being "emerging” status within research-intensive institutions to the mainstream, infrastructure must be created to support faculty to do this work. I have described four specific strategies institutions could develop to support community-engaged scholarship: (a) revise promotion and tenure documents to recognize it; (b) update IRB reviews to support it; (c) earnark internal funding specifically for it; and (d) create networks to spread it.

With these supports, institutions could unleash the potential of faculty to use their academic expertise to solve real-world problems and help realize the vision of the community-engaged university. 


\section{References}

Allen, M. L., Culhane-Pera, K. A., Pergament, S. L., \& Call, K. T. (2010). Facilitating research faculty participation in CBPR: Development of a model based on key informant interviews. Clinical and Translational science, 3 (5), 233-238. https://doi.org/10.1111/j.1752$\underline{8062.2010 .00231 . x}$

Balazs, C. L., \& Morello-Frosch, R. (2013). The three Rs: How community-based participatory research strengthens the rigor, relevance, and reach of science. Environmental Justice, 6 (1), 916. https://doi.org/10.1089/env.2012.0017

Beck, J. G., Castonguay, L. G., Chronis-Tuscano, A., Klonsky, E. D., McGinn, L. K., \& Youngstrom, E. A. (2014). Principles for training in evidence-based psychology:

Recommendations for the graduate curricula in clinical psychology. Clinical Psychology: Science and Practice, 21 (4), 410-424. https://doi.org/10.1111/cpsp.12079

Bogart, L. M., \& Uyeda, K. (2009). Community-based participatory research: Partnering with communities for effective and sustainable behavioral health interventions. Health Psychology, 28, 391-393. https://doi.org/10.1037/a0016387

Carnegie Foundation for the Advancement of Teaching. (2018). 2020 Carnegie Elective Community Engagement Classification Application Form. Retrieved from https://drive.google.com/file/d/1rC5 BQtzGGmNFp94kMw19qwV8OIHggKK/view

Carnegie Classification of Institutions of Higher Education. (2018). Retrieved from http://carnegieclassifications.iu.edu/classification_descriptions/basic.php

Carnegie Foundation for the Advancement of Teaching, 2017. Carnegie Selects Colleges and Universities for 2015 Community Engagement Classification. Retrieved from https://www.carnegiefoundation.org/newsroom/news-releases/carnegie-selects-collegesuniversities-2015-community-engagement-classification/.

Collins, S. E., Clifasefi, S. L., Stanton, J., The LEAP Advisory Board, Straits, K. J. E., GilKashiwabara, E., Rodriguez Espinosa, P., Nicasio, A. V., Andrasik, M. P., Hawes, S. M., Miller, K. A., Nelson, L. A., Orfaly, V. E., Duran, B. M., \& Wallerstein, N. (2018, January 22). Community-Based Participatory Research (CBPR): Towards Equitable Involvement of Community in Psychology Research. American Psychologist. Advance online publication. https://doi.org/10.1080/13576280110051055

Crosby, L. E., Parr, M. W., Smith, M. T., \& Mitchell, M. J. (2013 March). The community leaders institute: an innovative program to train community leaders in health research. Academic medicine: journal of the Association of American Medical Colleges, 88 (3), 335-342. https://doi.org/10.1097/ACM.0b013e318280d8de 
Israel, B. A., Schulz, A. J., Parker, E. A., \& Becker, A. B. (2001). Community-based participatory research: Policy recommendations for promoting a partnership approach in health research. Education for health, 14 (2), 182-197. https://doi.org/10.1080/13576280110051055

Jacquez, F. (2014). Demonstrating Impact as a Community-Engaged Scholar within a Research University. Metropolitan Universities, 25 (2), 14-26. Retrieved from https://journals.iupui.edu/index.php/muj/article/view/20570/20170

Jacquez, F. M., Vaughn, L. \& Suarez-Cano, G.* (2018). Implementation of a Stress Intervention with Latino Immigrants in a Non-Traditional Migration City. Journal of Immigrant and Minority Health, ePub ahead of print. https://doi.org/10.1007/s10903-018-0732-7

Jacquez, F.M., Vaughn, L.M., Zhen-Duan, J.* \& Graham, C. (2016). Healthcare use and barriers to care among latino immigrants in a new migration area. Journal for Healthcare for the Poor and Underserved, 27 (4), 1761-1778. https://doi.org/10.1353/hpu.2016.0161

Mikesell, L., Bromley, E., \& Khodyakov, D. (2013). Ethical community-engaged research: A literature review. American Journal of Public Health, 103 (12), e7-e14. https://doi.org/10.2105/AJPH.2013.301605

Nyden, P. (2003). Academic incentives for faculty participation in community-based participatory research. Journal of General Internal Medicine, 18 (7), 576-585. https://doi.org/10.1046/j.1525-1497.2003.20350.x

Shore N, Park A, Castro P, Wat E, Sablan-Santos L, Isaacs ML, Freeman E, Cooks JM, Drew E, Seifer SD. (2014). Redefining Research Ethics Review: Case Studies of Five Community-Led Models. Seattle, WA: Community-Campus Partnerships for Health. Retrieved from https://community-wealth.org/content/redefining-research-ethics-review-case-studies-fivecommunity-led-models

Swearer Center at Brown University. (2018). Carnegie Classification for Community Engagement. Retrieved from https://www.brown.edu/swearer/carnegie

Tamariz, L., Medina, H., Taylor, J., Carrasquillo, O., Kobetz, E., \& Palacio, A. (2015). Are research ethics committees prepared for community-based participatory research? Journal of Empirical Research on Human Research Ethics, 10 (5), 488-495.

https://doi.org/10.1177/1556264615615008

Vaughn, L. M., Jacquez, F., Marschner, D.*, \& McLinden, D. (2016). See what we say: Using concept mapping to visualize latino immigrant's strategies for health interventions. International Journal of Public Health, 61 (7), 837-845. https://doi.org/10.1007/s00038-016-0838-4

Vaughn, L. M., Jacquez, F. M., \& Zhen-Duan, J.* (2018). Perspectives of community coresearchers about group dynamics and equitable partnership within a community-academic research team. Health Education \& Behavior, ePub ahead of print. https://doi.org/10.1177/1090198118769374 
Vaughn, L. M., Jacquez, F., Zhen-Duan, J., Graham, C., Marschner, D., Peralta, J., García, H., Recino, M., Maya, M., Maya, E., Cabrera, M., \& Ley, I. (2017). Latinos Unidos por la salud: The process of developing an immigrant community research team. Collaborations: A Journal of Community-Based Research and Practice, 1 (1). Retrieved from http://scholarlyrepository.miami.edu/collaborations/vol1/iss1/2

Topmiller, M., Zhen-Duan, J., Jacquez, F. J., \& Vaughn, L. M. (2016). Place matters in nontraditional migration areas: Exploring barriers to healthcare for latino immigrants by region, neighborhood, and community health center. Journal of Racial and Ethnic Health Disparities, 4 (6), 1214-1223. https://doi.org/10.1007/s40615-016-0329-6

Wilson, E., Kenny, A., \& Dickson-Swift, V. (2018). Ethical challenges of community based participatory research: Exploring researchers' experience. International Journal of Social Research Methodology, 21 (1), 7-24. https://doi.org/10.1080/13645579.2017.1296714

Zhen-Duan, J.*, Jacquez, F., \& Vaughn, L., M. (2017). Demographic characteristics associated with barriers to healthcare among Mexican and Guatemalan immigrants in a nontraditional destination area. Family \& Community Health, 40 (2), 101-111.

https://doi.org/10.1097/FCH.0000000000000141 


\section{Author Information}

Farrah M. Jacquez, Ph.D.

Associate Professor, Psychology

University of Cincinnati

4150N EDWARDS 1 Edwards Center

Telephone: 513-556-5124

Email: jacquefh@ucmail.uc.edu

Web: https://sites.google.com/site/ucpitchlab/

Farrah M. Jacquez is a licensed clinical psychologist and associate professor of psychology at the University of Cincinnati. Her work is focused on community-partnered approaches to health equity. Since arriving at UC in 2008 , she has collaborated with community partners to secure over $\$ 250,000$ of grant funding for community research with direct community benefit. She is interested in utilizing community-based research methods to address health disparities.

${ }^{i}$ Research savvy refers to the strategic decisions community engaged researchers need to make to successfully navigate the tenure process. 